\title{
Physiology and biochemistry of reduction of azo compounds by Shewanella strains relevant to electron transport chain
}

\author{
Yi-Guo Hong • Ji-Dong Gu
}

Received: 10 July 2010 /Revised: 2 August 2010 /Accepted: 3 August 2010 /Published online: 13 August 2010

(C) The Author(s) 2010. This article is published with open access at Springerlink.com

\begin{abstract}
Azo dyes are toxic, highly persistent, and ubiquitously distributed in the environments. The large-scale production and application of azo dyes result in serious environmental pollution of water and sediments. Bacterial azo reduction is an important process for removing this group of contaminants. Recent advances in this area of research reveal that azo reduction by Shewanella strains is coupled to the oxidation of electron donors and linked to the electron transport and energy conservation in the cell membrane. Up to date, several key molecular components involved in this reaction have been identified and the primary electron transportation system has been proposed. These new discoveries on the respiration pathways and electron transfer for bacterial azo reduction has potential biotechnological implications in cleaning up contaminated sites.
\end{abstract}

Keywords Bacterial azo reduction .

Electron transport chain · Physiology and biochemistry

\section{Introduction}

Azo dyes, aromatic moieties linked together by azo $(-N=$ $\mathrm{N}-$ ) chromophores, represent the largest class of dyes used

Y.-G. Hong $(\bowtie)$

Key Laboratory of Tropical Marine Environment

Dynamics (LED), South China Sea Institute of Oceanography,

Chinese Academy of Sciences,

164 Xingang Road West,

Guangzhou 510301, People's Republic of China

e-mail: yghong@scsio.ac.cn

J.-D. Gu

School of Biological Sciences, The University of Hong Kong, Pokfulam Road,

Hong Kong, SAR, People's Republic of China in textiles, leather, plastics, cosmetics, and food industries (Zolinger 1991). Because some of them are toxic, highly persistent, and ubiquitously distributed in the environments, azo dyes are regarded as environmental pollutants (Pearce et al. 2003; Maguire 1992; Zolinger 1991; Selvam et al. 2003; Stolz 2001). The release of these compounds into the environment not only presents an aesthetic problem due to their colors, but also threatens aquatic life and eventually affects human health (Brown and DeVito 1993; Chung and Cerniglia 1992).

Anaerobic azo dye reduction is the reductive cleavage of azo linkages, i.e., the transfer of reducing equivalents resulting in the formation of aromatic amines. As aromatic amines are generally colorless, azo dye reduction is also referred to as azo dye decolourization. Several review articles have summarized the studies on bacterial azo dye reduction (Banat et al. 1996; Bumpus 1995; Chung et al. 1992; Chung and Stevens 1993; Delee et al. 1998; Levine 1991; McMullan et al. 2001; Stolz 2001; Walker 1970). In fact, most of the studies focus on the "azoreductases" and two types of NAD(P)H- and FMN-dependent cytoplasmic "azoreductases" have been isolated and characterized (Zimmermann et al. 1982, 1984; Suzuki et al. 2001; Maier et al. 2004; Blümel and Stolz 2003; Rafii and Cerniglia 1993; Ghosh et al. 1992, 1993). But these enzymes are shown to be ineffective in vivo, as their reductase activity is only significant when using cell extracts and not with intact cells (Russ et al. 2000; Blümel et al. 2002). Therefore, the mechanism of bacterial azo reduction in vivo has become a topic attracting much attention. In nature, accumulative evidences have shown that bacterial azo reduction is a nonspecific reaction in vivo, and the capability of reducing azo dye can be considered as a universal property of bacteria incubated anaerobically. The non-specific process may be the main driver to decolorize azo dyes in the nature 
environment and in bio-reactors (Stolz 2001; Khalid et al. 2010). Recent investigations of bacterial azo reduction have led to a new recognition that azo reduction by certain bacteria is related to the electron transport chain on the cellular membrance. This kind of biochemical reaction is not simply catalyzed by a single enzyme, but by a complicated electron transport system in vivo. This review focuses on the recent advances in physiology and biochemistry of bacterial reduction of azo compounds relevant to the electron transport chain.

\section{Azo reduction coupled to oxidation of electron donors}

Bacterial decolorization is a wide spread phenomenon under anaerobic conditions (Pearce et al. 2003). It is known that a variety of microorganisms can reduce azo dyes, including pure cultures of obligate anaerobic strains (e.g., Bacteroides sp., Eubacterium sp., Clostridium sp.) (Rafii et al. 1990; Bragger et al. 1997), and facultative anaerobic strains (e.g., Sphingomonas sp. strain BN6, Pseudomonas luteola sp., Proteus vulgaris, Streptococcus faecalis) (Kudlich et al. 1997; Hu 1994; Dubin and Wright 1975; Scheline et al. 1970). Van der Zee et al. (2001a, b) showed that the azo reduction by mixed culture in anaerobic granular sludge could be stimulated when volatile fatty acids are readily available as electron donors. However, the effect of electron donors (mainly referred as short-chain fatty acids) on bacterial azo reduction has been investigated only with several pure cultures of Shewanella group in define carbon source, including Shewanella decolorationis S12 (Xu et al. 2005), Shewanella strain J18 143 (Pearce et al. 2006), and Shewalella oneidensis MR-1 (Brigé et al. 2008), which are good model system for studying the relationship between the oxidation of electron donors and reduction of azo dyes. $S$. decolorationis $\mathrm{S} 12$ can use $\mathrm{H}_{2}$, formate, lactate and pyruvate as sole electron donor for the reduction of various azo dyes in a defined medium, but acetate, propionate, salicylate, glycerin, ethanol, citrate and succinate are not effective electron donor for azo reduction. In the electron donor-free controls, almost no azo reduction could be measured (Hong et al. 2007b). Similar experiments were performed by Brigé et al. (2008) with $S$. oneidensis MR-1R. Further analysis reveals that there is a linear relationship between the consumption of formate and reduction of amaranth when excess amaranth and limiting formate were in the culture media. The disappearance of amaranth (azo reduction) was accompanied by stoichiometrical consumption of formate over time of incubation. Based on the calculation, formate consumption and amaranth reduction were in good agreement for the following reaction: $\mathrm{Ar} 1-\mathrm{N}=\mathrm{N}-\mathrm{Ar}_{2}+2 \mathrm{COOH}-+2 \mathrm{H}_{2} \mathrm{O} \rightarrow \mathrm{Ar} 1-\mathrm{NH}_{2}+$ $\mathrm{H}_{2} \mathrm{~N}-\mathrm{Ar}_{2}+2 \mathrm{HCO}_{3}^{-}+2 \mathrm{H}^{+}$(Hong et al. 2007a). In addition, both Shewalella sp. strain J18 143 and S. oneidensis MR-1 are found to reduce high concentrations of dyes at rates that strongly depend on the type of donors used among acetate, formate, lactate, and nicotinamide adenine dinucleotide (NADH), formate is the optimal electron donor among them (Pearce et al. 2006; Brigé et al. 2008). Moreover, toluene and aniline can also serve as electron donors for anaerobic azo reduction by strain S12, suggesting that bacteria are capable of azo reduction coupled to the transformation of toxic organic substances simultaneously (Hong et al. 2007a, b, c). Besides Shewanella strains, several other azo-reducing bacteria, including Citrobacter, Acinetobacter, Pseudomonas can reduce azo compounds with molecular hydrogen $\left(\mathrm{H}_{2}\right)$ or some short-chain fatty acids as electron donors (Hong et al. 2008a), which suggests that the coupling of the oxidation of electron donors to the reduction of azo compounds may be a universal biochemical process in nature.

\section{Molecular components involved in bacterial azo reduction}

The first study linking the azo reduction to the bacterial electron transport chain was published in 1997 by Kudlich et al. (1997), in which anaerobic reduction of azo dyes by Sphingomonas sp. strain BN6 occurred both in the cytoplasmic and membrane fractions. In contrast, anaerobic azo reduction in strain $\mathrm{S} 12$ occurs almost exclusively in the membrane fraction. However, there is little azo reductase activity in the cytoplasmic and periplasmic fractions. In addition, membrane vesicles (MVs) are capable of azo reduction without an external redox mediator, suggesting that the azo reduction by strain S12 is a direct enzymatic process. Freshly prepared MVs of strain S12 did effectively reduce azo compounds with $\mathrm{H}_{2}$, formate or lactate as the electron donor. If membrane vesicles are treated with heat, no azo reduction could be detected. These results show that the membrane fraction contains all of the essential components required for electron transport from the electron donors to the azo compounds resulting in effective azo reduction (Hong et al. 2007a, 2009).

Experiments using specific inhibitors showed that anaerobic azo reduction both in the bacterial cells in vivo and in the membrane vesicles are inhibited by specific respiratory inhibitors including $\mathrm{Cu}^{2+}$ ions, dicumarol, stigmatellin, metyrapone, demonstrating that the reduction process is catalyzed by a multi-component system including dehydrogenases, menaquinones, cytochromes and a deduced terminal azo reductase (Hong et al. 2007a, 2009). Brigé et al. (2008) further identify the molecular components involved in the decolorization process by $S$. oneidensis MR-1 comprehensively. With the method of 
constructing mutants from the model organism generated by random transposon and targeted insertional mutagenesis, it is proven that decolorization is an extracellular reduction process requiring a multi-component electron transfer pathway that consists of cytoplasmic membrane, periplasmic and outer membrane (OM) components (Hong et al. 2007a). Menaquinones and the cytochrome CymA (tetrahaem quinol dehydrogenase) are the crucial cytoplasmic membrane components involved in the pathway, which then branches off via a network of periplasmic cytochromes to three outer membrane cytochromes. MtrA (periplasmic protein $c$-type cytochrome) and OmcB (decaheme $c$-type cytochrome in the $\mathrm{OM}$ ) are the key proteins of this network in the periplasm and outer membrane, respectively (Brigé et al. 2008). Experiments by Brigé et al. (2008) confirmed that the MTRA mutant was not completely deficient in dye reduction; therefore additional proteins are possibly involved in the intermembrane electron transport required for extracellular dye reduction. OmcB is potential dye reductases in OM. Analysis revealed that OmcA (decaheme $c$ type cytochrome) mutant only a small decrease of the azo reduction rate, while the reduction rates of the $\mathrm{OmcA} /$ OmcB double mutant were significantly slower relative to its parents, suggests that OmcA and $\mathrm{OmcB}$ exhibit a interaction for reduction of azo dyes, similar to previously characteristic for the reduction of Fe(III)-NTA. The multihaem cytochromes MtrF, OmcA and OmcB may fulfil a function as terminal dye reductase (Brigé et al. 2008). In addition, Hya (a periplasmically oriented Ni-Fe hydrogenase) is identified as an uptake hydrogenase for hydrogendependent dissimilatory azo reduction by $S$. decolorationis S12 (Hong et al. 2008b).

A mutant S12-22 is constructed by Chen et al. (2010), which has a transposon insertion in ccmA gene. As ccmA is the essential component of an $\mathrm{ABC}$ transporter, required for the maturation of $c$ cytochromes (Thöny-Meyer et al. 1995; Bouhenni et al. 2005), the mutant S12-22 contains much lower level of $c$-type-heme-containing cytochromes than those of wild type S12. The mutant S12-22 cannot use formate as the sole electron donor for azo reduction either in vivo or in vitro. This study provides strong evidence that $c$-type cytochromes play a very important role in the electron transport for azo reduction. The genome sequence of $S$. oneidensis MR-1, for example, contains 42 cytochrome $c$ genes (Heidelberg et al. 2002; Meyer et al. 2004). The $c$-type cytochromes consist of an apoprotein in which a heme (protoheme IX) cofactor is covalently bound as their prosthetic group, and they are often the major electron transfer proteins in prokaryotic anaerobic respiratory chains (Thöny-Meyer et al. 1995). Furthermore, proteomic data reveals that most of the membrane proteins of strain S12 in azo reduction are similar to those under Fe (III) reduction, but FdnH (Formate dehydrogenase) and FrdB (Fumarate reductase) are expressed specifically in azo reduction and NqrA-2 $\left(\mathrm{Na}^{+}\right.$-translocating NADH-quinone reductase subunit $A$ and DctP (C4-dicarboxylate-binding periplasmic protein) showed relative over expression in azo reduction compared with Fe (III) reduction (Wang et al. 2010).

Azoreductase would be an important molecular biochemical component for this kind of azo reduction. It is possible that non-specific enzymes may be exist in many anaerobic and facultative anaerobic strains to reduce azo dyes under anaerobic conditions. Brigé et al. (2008) suggested that OmcB could act as an azo reductase, but there is no clear evidence available for the existence of specific azo reductases in anaerobically grown bacteria.

A hypothetical chemisomotic model of azo respiration is shown in Fig. 1 In this model the membrane-associated, cytoplasmic-oriented formate dehydrogenase or hydrogenase is the primary dehydrogenase. The membrane-bound, putative azo reductase functions as the terminal reductase. The electrons produced by the primary dehydrogenase are transported through the electron transport chain causing an electrochemical proton-motive force to be generated across the membrane, driving ATP synthesis. However, the precise mechanism of microbial anaerobic azo respiration has not been elucidated clearly at present.

\section{Energy conservation in the dissimiltary bacterial azo reduction}

Through the more than 3.5 billion years of evolutionary history of life, prokaryotes have acquired the ability to use a broad range of electron-accepting substances and bacterial respiration is a flexible process for a changing environment (Richardson 2000). Shewanella species are highly advanced among microbes in their ability to exploit these diverse arrays of electron acceptors (Tiejie 2002). Generally, energy generation is a by-product of electron transfer cross the membrane protein, ATPase. Thermodynamic calculations indicate that, for per electron transferred, coupling formate or $\mathrm{H}_{2}$ oxidation to azo reduction of amaranth has the potential to yield enough energy to sustain microbial growth. The growth data demonstrates that strain S12 is indeed capable of using the azo bond as a terminal electron acceptor for energy conservation under anaerobic condition (Hong et al. 2007a). ATP synthesis was repressed by ATPase inhibitor $N, N^{\prime}$ dicyclohexylcarbodiimide. These results are consistent with the chemiosmotic interpretation of energy generation by MVs and offer crucial evidence for the mechanism of microbial azo reduction at the subcellular level (Hong et al. 2009).

When electrons move from a reductant to an acceptor with a more positive redox potential, free energy is released. The $\Delta G^{\circ \prime}$ of the reaction is directly related to the magnitude of the difference between the reduction 


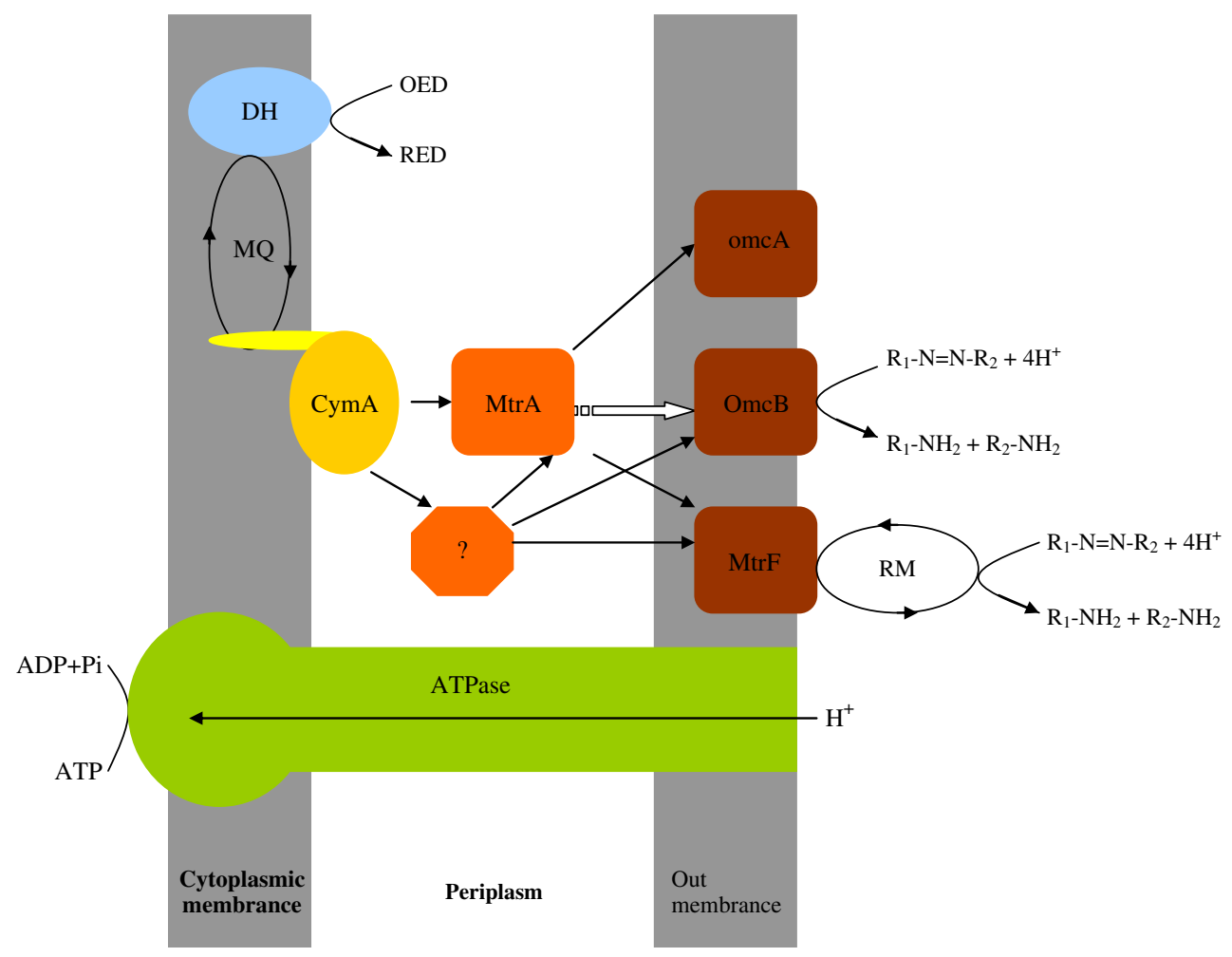

Fig. 1 Chemiosmotic model of the azorespiration electron transport chain in Shewanella decolorationis S12. When electron donor is oxided from reduced type $(R E D)$ into oxided one $(O E D)$ in the cytoplasmic membrane, electrons enter the menaquinone $(M Q)$ pool via membrane-bound dehydrogenase $(D H)$ from which they are transferred to CymA. The multihaem cytochromes MtrA and OmcB proteins play the key roles for the downstream electron transport of CymA, yet alternative routes of electron flow to the dyes via a network of cytochromes c (?) appear to be present. The multihaem

potential of the two couples $\left(\Delta E^{\circ}\right) . E^{\circ}$ values for ordinary primary electron donors are between 430 and $290 \mathrm{mV}$, and for azo compounds between -180 to $-450 \mathrm{mV}$ (Rau et al. 2002; Rau and Stolz 2003). Thermodynamic calculations have clearly indicated that, for per electron transferred, coupling formate, $\mathrm{H}_{2}$ or lactate oxidation to azo reduction of amaranth has the potential to yield energy sustain microbial growth.

When electrons move from a reductant to an acceptor with a more positive redox potential, free energy is released. The $\Delta G^{\circ \prime}$ of the reaction is directly related to the magnitude of the difference between the reduction cytochromes $\mathrm{MtrF}, \mathrm{OmcA}$, and $\mathrm{OmcB}$ may fulfill a function as terminal azoreductase, which can interact with azo dyes directly or through the redoxic mediators indirectly leading to the reduction eventually. The process of electron transport coupled with the $\mathrm{H}^{+}$ transfer from inner membrane to outer membrane and the chemical energy was transformed into electrical potential energy, which gets across special channels of $F_{0} F_{1}$ ATPase along proton electrical gradients; these gradients can drive ATP synthesis (Brigé et al. 2008; Hong et al. 2007a)

potential of the two couples $\left(\Delta E^{\circ \prime}\right)$. The lager the $\Delta E^{\circ \prime}$, the greater the amount of free energy made available, as is evident from the Eq. 1 below.

$\Delta G^{\mathrm{o}^{\prime}}=-n \mathrm{~F} \Delta E^{\mathrm{o}^{\prime}}$

In which $\Delta G^{\circ \prime}$ is standard free energy change, $\Delta E^{\circ \prime}$ is standard redox potential change, $n$ is the number of electrons transferred and $\mathrm{F}$ is the Faraday constant ( $23.062 \mathrm{cal} / \mathrm{mole}$-volt or $96.494 \mathrm{~kJ} / \mathrm{mole}-\mathrm{molt})$. Free energy released from dissimilatory azo reduction by $S$. decolorationis $\mathrm{S} 12$ with formate as electron donor:

$$
\begin{aligned}
& \Delta E^{\circ \prime}=-0.43 \\
& \Delta E^{\circ \prime}=0.25 \\
& \mathrm{~V}=-262.49 \mathrm{~kJ}
\end{aligned}
$$

Every mole ATP synthesis needs $30.53 \mathrm{~kJ}$ energy. When 1 mole amaranth is reduced, $252.07 \mathrm{~kJ}$ energy can be released corresponding $8.25 \mathrm{~mol}$ ATP in theory. If $4 \mathrm{~mol}$
ATP are synthesized when 1 mole amaranth is being reduced in fact, the rate of using energy is about. 47.94\%. With same calculation method, the rate of using energy can 
be figured out when $\mathrm{H}_{2}$ and lactate are used as electron donor $46.52 \%$ and $72.73 \%$, respectively.

The theoretical maximum ATP/e ratio, (nATP/ne) max $_{\text {, }}$ is calculated from the $\Delta G^{\circ \prime}$ and the $\Delta E^{\circ}$ of azoduction by $\mathrm{H}_{2}$ or formate, according to Eq. 2 where $\mathrm{F}$ represents the Faraday constant:

$$
(\mathrm{nATP} / \mathrm{ne}) \max =\Delta E^{\mathrm{o}^{\prime}} \mathrm{F} / \Delta G^{\prime} \mathrm{p}
$$

With $\Delta G^{\prime} p=50 \mathrm{~kJ} / \mathrm{mol}$ ATP, the maximum ATP/e ratio is obtained as 1.27 and 1.31. Using this value and the number of protons transported across the membrane for the synthesis of ATP, the maximum $\mathrm{H}^{+} / \mathrm{e}$ ratio is calculated to be 2.0. This means that the $\mathrm{H}^{+} / \mathrm{e}$ ratio of azo respiration of strain $\mathrm{S} 12$ should be either 2 or 1 , if the $\mathrm{H}^{+} / \mathrm{e}$ ratio has to be an integer number. The corresponding values of the ATP/e ratio would be 0.61 and 0.62 , respectively.

\section{Extracellullar electron transportation in the bacterial azo reduction}

Many dyes are polar and/or large molecules which are unlikely to diffuse through the cellular membrane (Zolinger 1991). Bacterial dye reduction is therefore hypothesized to be a mainly extracellular process (Keck et al. 1997; Kudlich et al. 1997; Pearce et al. 2003). One possibility is that the bacteria establish a link between azo dyes and outer membrance protein directly. But evidence concerning this direct extracellular reduction process has not been demonstrated. However, decolorization can be catalyzed by microbially excreted (Keck et al. 1997) or artificial (Kudlich et al. 1997; Rau et al. 2002) redox mediators. This hypothesis has been received some acceptance. Such a system implies that the transfer of reducing equivalents from an intracellular electron transport chain to the mediators would reduce the extracellular dye nonenzymatically.

Extracellular electron transfer may be a general mechanism for microorganisms to generate energy for cell growth and/or maintenance. Specifically, bacteria can use redoxactive small organic molecules, generated either outside or inside the cells, to shuttle electrons between reduced and oxidized compounds (Hernandez and Newman 2001; Gralnick and Newman 2007). It was reported that the reduction of AQDS by Shewanella putrefaciens proceeds via excretion of unidentified quinones for extracellular electron transfer and it was suggested that the biological reduction of azo compounds might also involve a similar mechanism (Newman and Kolter 2000). In general, the redox mediators, for example, AQDS, AQS, and HNQ, can also be used as terminal electron acceptors for bacterial respiration (Lovley and Coates 2000). Then humic sub- stances can shuttle electrons between the humic reducing microorganisms and azo compounds, and the azo reduction is accelerated (Hong et al. 2007c; Rau et al. 2002; Van der Zee et al. 2001a, b). Aside from these quinones, Fe(III) can stimulate bacterial azo dye reduction (Xu et al. 2007), suggesting that $\mathrm{Fe}$ (III) also can be involved in the extracellular electron transfer process.

\section{Theoretical and applied significance}

Anaerobic respiration by bacteria is an essential metabolic process. Microorganisms are often able to use a diverse range of electron acceptors, depending on the environmental conditions to which they are exposed (Richardson 2000). Under anaerobic conditions, bacteria can conserve energy using diverse noxious substances as terminal electron acceptors. Novel forms of anaerobic respiration have been and will continue to be discovered (Lovley and Coates 2000). These new discoveries have important environmental and biotechnological implications for these types of biochemical reactions impact the degradation of environmental contaminants and the cycling of organic carbon as well as many inorganic elements. Furthermore, anaerobic respiration is increasingly recognized as a strategy for the remediation of environmental contaminants (Lovley 2001, 2003). It is evident that microbial dissimilatory azo reduction is a respiratory process and this biochemical reaction process can be called azo respiration. This new recognized form of anaerobic respiration expands the potential electron acceptors known for microbial energy conservation.

This newly recognized microbial anaerobic respiration may also have important environmental and biotechnological implications for the treatment of dye-containing wastewater and bioremediation of sites contaminated with azo dyes. Based on this concept, anaerobic azo reduction by Shewanella strains is a biochemical process coupling the oxidation of electron donors. In general, both mechanisms using redox mediators and direct enzymatic reduction could involve in this electron transport process. As such, at least three pathways, adding electron donors, adding redox mediators and regulating the activity of cytochromes proteins, may stimulate the reduction of azo dyes. Moreover, since toluene and aniline can also serve as electron donors for anaerobic azo reduction by strain $\mathrm{S} 12$, bacteria capable of dissimilatory azo reduction may be able to couple the transformation of toxic organic substances to the reduction of azo compounds simultaneously. Shewanella strains are able to grow both aerobically and anaerobically in many different environments, and most of them are not pathogens to humans or other organisms of the ecosystem (Hau and Gralnick 2007). These properties make them ideal 
bacteria for bioremediation of environments contaminated with azo dyes and other toxic organic chemicals.

Acknowledgement The author gratefully acknowledges the support of the National Natural Science Foundation (30800032), Knowledge Innovation Key Project of The Chinese Academy of Sciences (KZCX2-YW-QN207) and the Foundation of the President of the Chinese Academy of Sciences (07YQ091001) and K.C. Wong Education Foundation, Hong Kong.

Open Access This article is distributed under the terms of the Creative Commons Attribution Noncommercial License which permits any noncommercial use, distribution, and reproduction in any medium, provided the original author(s) and source are credited.

\section{References}

Banat IM, Nigam P, Singh D, Marchant R (1996) Microbial decolorization of textile dye-containing effluents: a review. Biores Technol 58:217-227

Blümel S, Stolz A (2003) Cloning and characterization of the gene coding for the aerobic azoreductase from Pigmentiphaga kullae K24. Appl Microbiol Biotechnol 62:186-190

Blümel S, Knackmuss J, Stolz A (2002) Molecular cloning and characterization of the gene coding for the aerobic azoreductase from Xenophilus azovorans KF46F. Appl Environ Microbiol 68:3948-3955

Bouhenni R, Gehrke A, Saffarini D (2005) Identification of genes involved in cytochrome c biogenesis in Shewanella oneidensis, using a modified mariner transposon. Appl Environ Microbiol 71:4935-4937

Bragger JL, Lloyd AW, Soozandehfar SH, Bloomfield SF, Marriott C, Martin GP (1997) Investigations into the azo reducing activity of a common colonic microorganism. Int $\mathrm{J}$ Pharm 157:61-71

Brigé A, Ba M, Borloo J, Buysschaert G, Devreese B, Van Beeumen JJ (2008) Bacterial decolorization of textile dyes is an extracellular process requiring a multicomponent electron transfer pathway. Microbiol Biotechnol 1:40-52

Brown MA, DeVito SC (1993) Predicting azo dye toxicity. Crit Rev Environ Sci Technol 23:249-324

Bumpus JA (1995) Microbial degradation of azo dyes. Prog Ind Microbiol 32:157-176

Chen X, Xu M, Wei J, Sun G (2010) Two different electron transfer pathways may involve in azoreduction in Shewanella decolorationis S12. Applied Microbiology and Biotechnology 86:743-751

Chung KT, Cerniglia CE (1992) Mutagenicity of azo dyes: structureactivity relationships. Mutat Res 77:201-220

Chung KT, Stevens SEJ (1993) Degradation of azo dyes by environmental microorganisms and helminths. Environ Toxicol Chem 12:2121-2132

Chung KT, Stevens SEJ, Cerniglia CE (1992) The reduction of azo dyes by the intestinal microflora. Crit Rev Microbiol 18:175197

Delee W, O’Neill C, Hawkes FR, Pinheiro HM (1998) Anaerobic treatment of textile effluents: a review. J Chem Technol Biotechnol 73:323-335

Dubin P, Wright KL (1975) Reduction of azo food dyes in cultures of Proteus vulgaris. Xenobiotica 5:563-571

Ghosh DK, Mandal A, Chaudhuri J (1992) Purification and partial characterization of two azoreductases from Shigella dysenteriae type 1. FEMS Microbiol Lett 98:229-234
Ghosh DK, Ghosh S, Sadhukhan P, Mandal A, Chaudhuri J (1993) Purification of two azoreductases from Escherichia coli K12. Ind J Exp Biol 31:951-954

Gralnick JA, Newman DK (2007) Extracellular respiration. Molecular Microbiol 65:1-11

Hau HH, Gralnick JA (2007) Ecology and biotechnology of the genus Shewanella. Annual Review Microbiol 61:237-258

Heidelberg J, Paulsen I, Nealson K, Gaidos E, Nelson W, Read T et al (2002) Genome sequence of the dissimilatory metal ion-reducing bacterium Shewanella oneidensis. Nat Biotechnol 20:1118-1123

Hernandez ME, Newman DK (2001) Extracellular electron transfer. Cell Mol Life Sci 58:1562-1571

Hong Y, Xu M, Guo J, Xu Z, Chen X, Sun G (2007a) Respiration and growth of Shewanella decolorationis $\mathrm{S} 12$ with an azo compound as sole electron acceptor. Appl and Environ Microbiol 73:64-72

Hong Y, Chen X, Guo J, Xu Z, Xu M, Sun G (2007b) Effects of electron donors and acceptors on anaerobic azo dyes reduction by Shewanella decolorationis S12. Appl Microbiol Biotechnol 74:230-238

Hong Y, GuoJ XuZ, Xu M, Sun G (2007c) Humic substances act as electron acceptor and redox mediator for microbial dissimilatory azoreduction by Shewanella decolorationis S12. J Microbiol Biotech 17:428-437

Hong Y, Guo J, Sun G (2008a) Characteristic and phylogenetic analysis of facultative anaerobic dissimilatory azo-reducing bacteria from anaerobic active sludge. Inter Biodeter Biodegrad 61:313-318

Hong Y, Guo J, Sun G (2008b) Identification of an uptake hydrogenase for hydrogen-dependent dissimilatory azoreduction by Shewanella decolorationis S12. Appl Microbiol Biotechnol 80:517-524

Hong Y, Guo J, Sun G (2009) Energy generation coupled to the azoreduction by the membranous vesicles from Shewanella decolorationis S12. J Microbiol Biotech 19:37-41

Hu TL (1994) Decolourization of reactive azo dyes by transformation with Pseudomonas luteola. Bioresource Technol 49:47-51

Keck A, Klein J, Kudlich M, Stolz A, Knackmuss H-J, Mattes R (1997) Reduction of azo dyes by redox mediators originating in the naphtalenesulfonic acid degradation pathway of Sphingomonas sp. strain NB6. Appl Environ Microbiol 63:3684-3690

Khalid A, Arshad M, Crowley DE (2010) Perspectives for improving azo dye biotreatment systems using bioaugmentation. In: Atacag Erkurt H (ed) The handbook of environmental chemistry: biodegradation of azo dyes, Vol. 9. Springer-Verlag, Berlin Heidelberg, pp 1-37

Kudlich M, Keck A, Klein J, Stolz A (1997) Localization of the enzyme system involved in the anaerobic degradation of azo dyes by Sphingomonas sp. BN6 and effect of artificial redox mediators on the rate of azo reduction. Appl Environ Microbiol 63:36913694

Levine WG (1991) Metabolism of azo dyes: implication for detoxification and activation. Drug Metabol Rev 23:253-309

Lovley DR (2001) Anaerobes to the rescue. Science 24:1444-1445

Lovley DR (2003) Cleaning up with genomics applying molecular biology to bioremediation. Nat Rev Microbiol 1:35-44

Lovley DR, Coates JD (2000) Novel forms of anaerobic respiration of environmental relevance. Current Opinion Microbiol 13:252-256

Maguire RJ (1992) Occurrence and persistence of dyes in a Canadian river. Water Sci Technol 25:265-270

Maier J, Kandelbauer A, Erlacher A, Cavaco-Paulo A, Gübitz GM (2004) A new alkali-thermostable azoreductase from Bacillus sp. strain SF. Appl Environ Microbiol 70:837-844

McMullan G, Meehan C, Conneely A, Nirby N, Robinson T, Nigam P, Banat IM, Marchant R, Smyth WF (2001) Mini Review: Microbial decolourisation and degradationof textile dyes. Appl Microbiol Biotechnol 56:81-87

Newman DK, Kolter R (2000) A role for excreted quinones in extracellular electron transfer. Nature 405:94-97 
Pearce CI, Lloyd JR, Guthrie JT (2003) The removal of colour from textile wastewater using whole bacterial cells: a review. Dyes Pigm 58:179-196

Pearce CI, Christie R, Boothman C, von Canstein H, Guthrie JT, Lloyd JR (2006) Reactive azo dye reduction by Shewanella strain J18 143. Biotechnol Bioeng 95:692-703

Rafii F, Cerniglia CE (1993) Comparison of the azoreductase and nitroreductase from Clostridium perfringens. Appl Environ Microbiol 59:1731-1734

Rafii F, Franklin W, Cerniglia CE (1990) Azoreductase activity of anaerobic bacteria isolated from human intestinal microflora. Appl Environ Microbiol 56:2146-2151

Rau J, Knackmuss HJ, Stolz A (2002) Effects of different quinoid redox mediators on the anaerobic reduction of ago dyes by bacteria. Environ Sci Technol 36:1497-1504

Rau J, Stolz A (2003) Oxygen-insensitive nitroreductases NfsA and $\mathrm{NfsB}$ of Escherichia coli function under anaerobic conditions as lawsone-dependent Azo reductases. Appl Environ Microbiol 69:3448-3455

Richardson DJ (2000) Bacterial respiration: a flexible process for a changing environment. Microbiol 146:551-571

Russ R, Rau J, Stolz A (2000) The function of cytoplasmic flavin reductases in the reduction of azo dyes by bacteria. Appl Environ Microbiol 66:1429-1434

Scheline RR, Nygaard RT, Longberg B (1970) Enzymatic reduction of the azo dye, acid yellow, by extracts of Streptococcus faecalis, isolated from rat intestine. Food Cosmet Toxicol 8:55-58

Selvam K, Swaminathan K, Keo-Sang C (2003) Microbial decolorization of azo dyes and dye industry effluent by Fomes lividus. World J Microbiol Biotechnol 19:591-593

Stolz A (2001) Basic and applied aspects in the microbial degradation of azo dyes. Appl Microbiol Biotechnol 56:69-80

Suzuki Y, Yoda T, Ruhul A, Sugiura W (2001) Molecular cloning and characterization of the gene coding for azoreductase from
Bacillus sp. OY12 isolated from soil. J Biol Chem 276:90599065

Tiejie JM (2002) Shewanella - the environmentally versatile genomes. Nat Biotech 20:1903-1904

Thöny-Meyer L, Fischer F, Kunzler P, Ritz D, Hennecke H (1995) Escherichia coli genes required for cytochrome c maturation. J Bacteriol 177:4321-4326

Van der Zee FP, Lettinga G, Field JA (2001a) Azo dye decolourisation anaerobic granular sludge. Chemosphere 44:1169-1176

van der Zee FP, Bouwman RH, Strik DP, Lettinga G, Field JA (2001b) Application of redox mediators to accelerate the transformation of reactive azo dyes in anaerobic bioreactors. Biotechnol Bioeng 75:691-701

Walker R (1970) The metabolism of azo compounds: a review of the literature. Food Cosmet Toxicol 8:659-676

Wang B, Xu M, Sun G (2010) Comparative analysis of membranous proteomics of Shewanella decolorationis S12 grown with azo compound or Fe (III) citrate as sole terminal electron acceptor. Appl Microbiol Biotechnol 86:1513-1523

Xu M, Guo J, Cen Y, Zhong X, Cao W, Sun G (2005) Shewanella decolorationnis sp. nov., a decoloraning bacterium isolated from an activated-sludge of wastewater treatment plant. Int J Syst Evol Microbiol 55:363-368

Xu M, Guo J, Kong X, Chen X (2007) Sun G (2007) Fe(III)-enhanced Azo Reduction by Shewanella decolorationis S12. Appl Microbiol Biotechnol 74:1342-1349

Zimmermann T, Kulla HG, Leisinger T (1982) Properties of purified Orange II azoreductase, the enzyme initiating azo dye degradation by Pseudomonas KF46. Eur J Biochem 129:197-203

Zimmermann T, Gasser F, Kulla HG, Leisinger T (1984) Comparison of two azoreductases acquired during adap tation to growth on azo dyes. Arch Microbiol 138:37-43

Zolinger H (1991) Color chemistry, 2nd edn. VCH, New York 